\title{
A ATUAÇÃO DAS INTERFACES NÃO-CONVENCIONAIS NA EDUCAÇÃO
}

\author{
Cristina Alba Wildt Torrezan - PPGIE/ UFRGS - crisaaw@ yahoo.com.br \\ Eliseo Berni Reategui - PPGIE/UFRGS - eliseoreategui@ gmail.com \\ Patrícia Alejandra Behar - PPGIE/ UFRGS - pbehar@terra.com.br \\ Patrícia da Silva Campelo Costa - PPGIE/ UFRGS - patricia.campelo@ yahoo.com
}

Resumo: Este artigo apresenta uma discussão acerca da inclusão de materiais educacionais digitais com interfaces não-convencionais no contexto escolar. Tais interfaces têm como característica uma forte interatividade entre a máquina e o sujeito. Visto que a geração digital de estudantes tem a oportunidade de utilizar tais interfaces em variados dispositivos, procura-se neste estudo relacionar algumas noções sobre a motivação com conceitos referentes à estética e à estesia, a fim de compreender como essas interfaces podem colaborar com a educação. Espera-se com isso ampliar a noção de interatividade na escola, de modo a colaborar na inserção de materiais educacionais digitais que promovam motivação e sensações fomentadas por experiências estéticas.

Palavras-chave: Tecnologia e educação, interfaces não-convencionais, materiais educacionais digitais

\section{THE ROLE OF NON-CONVENTIONAL INTERFACES ON EDUCATION}

Abstract: This article presents a discussion on the inclusion of digital educational material with non-conventional interfaces in learning contexts. Such interfaces are characterized by a strong man-machine interactivity. As the digital generation of students has the opportunity of using these interfaces in a variety of devices, we seek to establish the relationship between notions of esthetics and aesthesis and studies on motivation, in order to understand how these interfaces can collaborate on education. We hope the notion of interactivity can be expanded in school so as to endorse the inclusion of digital learning materials which may promote motivation and sensations fostered by esthetic experiences.

Keywords: Technology and education, non-conventional interfaces, digital learning materials

\section{Introdução}

Frente à expansão da internet e das tecnologias digitais, verifica-se a crescente aplicação dos dispositivos tecnológicos na educação. Segundo Behar (2009), a educação vive um momento de transformação, e os paradigmas presentes na sociedade não estão sendo suficientes para dar conta das relações, necessidades e desafios sociais. Conforme a autora, o modelo educativo atual privilegia o ensino tecnicista, que tem por objetivo preparar os indivíduos para desempenhar papéis específicos. Através dessa prática, os alunos têm dificuldade em relacionar o conteúdo estudado com a realidade, de modo a 
não se sentirem instigados a investigar um assunto. Além disso, visualiza-se um período de transição entre tecnologias analógicas e digitais, referentes ao planejamento e construção de práticas educativas.

Apoiando a aplicação da tecnologia digital na educação, as interfaces ${ }^{1}$ digitais favorecem a ação autônoma e investigativa do aluno sobre o material educacional digital $^{2}$. Além disso, vão ao encontro do perfil da atual geração digital ${ }^{3}$. Porém, devido à sua intimidade com a tecnologia digital, as interfaces consideradas tradicionais ou convencionais parecem afetar cada vez menos os nativos digitais (Veen e Vrakking, 2009). Surge assim uma crescente necessidade de tornar a navegação cada vez mais automática, de maneira a exigir do aprendiz um envolvimento maior, tornando o processo de aprendizagem mais interativo e significativo. As interfaces nãoconvencionais favorecem a adoção de tal postura, sendo essa mais questionadora e investigativa. Segundo Kirner (s.d.), a interface não-convencional é responsável por responder às ações do usuário com estímulos que afetam sua percepção, seus sentidos. O ambiente no contexto desse modelo compõe-se dos espaços real e artificial.”. Para efeitos de exemplificação, o autor apresenta a telepresença, a realidade virtual, a realidade aumentada e a realidade melhorada como sistemas "que têm em comum o acesso através de interfaces não-convencionais".

Dentro desta perspectiva, este estudo objetiva discutir como as interfaces nãoconvencionais podem afetar o usuário dentro de um contexto educacional, a partir de inserções de propostas que se baseiem em tais mecanismos. O intuito é instigar o debate a respeito de novas metodologias de aplicação das tecnologias digitais na educação de modo a apoiar significativamente o perfil da geração digital.

\section{Interface convencional e não-convencional}

A introdução das tecnologias digitais em distintas atividades cotidianas torna mais evidente o desenvolvimento de novas habilidades e competências referentes ao perfil da nova geração digital (Behar, 2009). O aluno, em especial as crianças e os adolescentes, convivem, muitas vezes, com interfaces que são consideradas nãoconvencionais, tais como nos videogames dotados de mecanismos que possibilitam interatividade corporal (também conhecidos por exergames). Conforme Kirner e Siscoutto (2007), essa peculiaridade do não-convencional é caracterizada pela impressão que o usuário tem de atuar "dentro do ambiente virtual, apontando, pegando, manipulando e executando outras ações sobre os objetos virtuais, em tempo real" (p.8). Ademais, dentre esses mecanismos não-convencionais, temos as interfaces hápticas, isto é, relativas ao tato, a partir das quais há uma "busca por dispositivos que permitam uma interação com os sistemas virtuais de modo sensoriamente similar às interações presentes no mundo físico" (Caetano, 2008). A partir de tais interfaces, o usuário pode utilizar de todos os seus sentidos durante a interação com a máquina, de modo que esse sujeito tenha a sensação de movimento e força, por exemplo. Segundo Smith (1997), a partir das interfaces hápticas há a inserção do sentido humano de tato no ambiente virtual, de modo a proporcionar ao usuário uma experiência de interação mais rica entre o homem e a máquina. Desse modo, neste trabalho a interface não-convencional é vista como um dispositivo que abarca a inserção de diferentes sentidos humanos na experiência de interação entre o objeto tecnológico e o sujeito.

O propósito da presente pesquisa é discutir de que modo a interatividade com tais interfaces pode influenciar o processo de aprendizado, de maneira a motivar o aprendiz que com elas entre em contato. Esses dispositivos podem apoiar o aluno em sua constituição do conhecimento, de modo que ele se sinta motivado e instigado a 
explorar algum conteúdo específico. Assim, aspectos relativos à motivação na aprendizagem (Schunk, Pintrich e Meece, 2008) também serão aqui abordados, a fim de serem examinadas as potencialidades do uso tecnológico no processo motivacional do aluno.

Este trabalho parte da seguinte questão-problema: Como o usuário pode ser afetado pelas interfaces não-convencionais? A partir desse questionamento, pretende-se, na presente pesquisa, colaborar para o desenvolvimento de novas aplicações das tecnologias digitais em materiais educacionais, de modo a incluir também as características das interfaces não-convencionais. O objetivo é colaborar na construção de Materiais Educacionais Digitais (MEDs) que sejam voltados à ação do sujeito e que apóiem o desenvolvimento de habilidades e competências emergentes na atual era digital.

\section{Interfaces não-convencionais na educação}

Pode-se pensar em algumas hipóteses sobre como as interfaces nãoconvencionais poderiam colaborar com esse novo perfil da geração digital. O aluno pode ter a oportunidade de encontrar sentido para o conteúdo de estudo, a partir da escolha e elaboração de estratégias para agir de modo autônomo. Além disso, a interface pode permitir que o aprendiz explore de forma mais ampla o MED, como em um laboratório de experimentos, ambiente no qual o aluno pode atuar livremente em busca de novas descobertas, através de uma interatividade ativa e sensorial. Além disso, em relação à questão afetiva, as interfaces não-convencionais atuam no sentido de considerar o usuário como parte integrante da interface, visto que sem a ação dele não há resposta do sistema. A relação entre máquina e aluno não se reduz à estímuloresposta, mas amplia essa vinculação, permitindo a exploração por parte do usuário. $\mathrm{O}$ aluno pode se sentir valorizado, pois é dada importância para o que ele pensa e como pensa, já que é fornecido espaço para que ele possa construir um efeito de sentido para o conteúdo estudado. Dado seu forte viés interativo, é possível que as interfaces nãoconvencionais influenciem nos processos de afetividade e motivação do aluno.

Greis e Reategui (2010) propõem um simulador educacional desenvolvido na área de física, construído em um mundo virtual. O sistema proposto explora diferentes elementos para enriquecer a experiência do aluno, tais como a interatividade, o desenvolvimento de narrativas mais complexas nas quais o próprio estudante pode se encontrar na cena, o refinamento estético do cenário construído e a diversificação das formas de apresentação do mesmo conteúdo da disciplina. Como enfatiza Aldrich (2009), tais elementos podem influenciar o modo como os estudantes interagem com o objeto de estudo, enriquecendo as experiências de aprendizagem.

Observar a relação específica entre motivação e o uso de tais interfaces pode ser um modo de examinar como esses dispositivos influenciam nos processos de aprendizagem a partir da afetação do aprendiz. A utilização dessas interfaces na educação é amplamente estudada, como se pode observar nos estudos a seguir.

Kirner e Zorzal (2005) apresentam uma proposta de utilização da realidade aumentada em ambientes digitais educacionais nos quais há foco no trabalho colaborativo entre os alunos. Segundo os autores, a fim de facilitar a interação entre pessoas localizadas em áreas geograficamente remotas, o uso da realidade aumentada pode fomentar a colaboração virtual. Para eles, a realidade aumentada seria possível quando há mistura do "cenário real com objetos virtuais gerados por computador", produzindo, então, "um único ambiente, sobreposto ao ambiente físico disposto na frente do computador" (p. 115). Conforme os autores, o nível de colaboração entre os 
participantes de uma interação mediada por realidade aumentada poderia ser potencializado. Isso se sucederia, pois há a oportunidade de ocorrerem inclusive interações face-a-face, através dessa fusão entre o ambiente físico e o virtual. Desse modo, a integração entre os alunos poderia ser fomentada a partir de recursos que possibilitem uma interação mais similar àquela estabelecida em contextos presenciais.

Em seu trabalho, Kaufman e Schmalstieg (2003) apresentam alguns usos potenciais da tecnologia de realidade aumentada no ensino de geometria. Assim como Kirner e Zorzal (2005), os autores também salientam a possibilidade de haver interação entre sujeitos/usuários, a partir do compartilhamento de um espaço virtual. Em tal espaço poderiam ocorrer interações simultâneas entre os alunos, a partir da interatividade com objetos virtuais e reais. Kaufman e Schmalstieg (2003) salientam que o uso de interfaces não-convencionais na educação pode contribuir para o aumento do interesse e motivação dos estudantes, de modo que a experiência de aprendizado possa ser potencializada.

Por sua vez, Liu et al (2007) estudaram o uso de interfaces de realidade mista, nas quais há sobreposição de gráficos computacionais no mundo real, em contexto escolar com aulas de ciências focalizadas no estudo do sistema solar. Conforme os autores, a realidade mista se diferenciaria da realidade aumentada e da realidade virtual, conforme a classificação a seguir: a) realidade mista: em uma interface com essa característica há integração entre objetos reais e virtuais, visto que os reais podem inclusive ser inseridos no mundo virtual; b) realidade aumentada: a partir desse dispositivo, objetos virtuais podem ser inseridos no mundo real; c) realidade virtual: a interatividade e a interação do usuário ocorrem em um mundo completamente virtual. Para os pesquisadores, a realidade mista oferece características que podem influenciar/afetar o aprendiz, tais como: aprendizagem experiencial, aprendizado colaborativo, imersão, interatividade e sensação de presença. Apesar de não mencionado no trabalho, é possível que tais peculiaridades expliquem a motivação que os usuários apresentam quando do uso de tais interfaces não-convencionais.

No trabalho de Kirner e Zorzal (2005), há a seguinte conclusão: “O emprego da realidade aumentada em ambientes educacionais contribui [...] na percepção, interação e motivação dos usuários". No entanto, apesar de considerações como essas, os trabalhos parecem ainda não ter se debruçado no conceito de motivação - como tal reação seria manifestada no sujeito e por que certas interfaces incitariam um comportamento motivacional dos usuários. Desse modo, esta pesquisa se atém a esses pontos, de maneira a investigar aspectos que apóiem a motivação e a ação crítica do sujeito a partir da interatividade aluno-interfaces não-convencionais.

\section{Motivação apoiada por interfaces não-convencionais}

No presente estudo, procuramos examinar como os estados afetivos do aluno podem ser afetados pelo uso de interfaces não-convencionais, consolidando-as como um possível mecanismo de motivação. Conforme Kirner (s.d), a partir dessas interfaces

o usuário é projetado dentro de um ambiente novo e interativo, através de dispositivos eletrônicos não convencionais. Tanto o desempenho, quanto a experiência do usuário no novo ambiente, dependem fortemente da interface homem-máquina e das características de interação com o ambiente real ou virtual.

Kirner e Siscoutto (2007) apontam para uma questão que parece sugerir o porquê de haver motivação a partir do uso de certas interfaces não-convencionais, como 
a realidade virtual, por exemplo. Conforme os pesquisadores, o usuário é instigado a agir, visto que interage em "um ambiente virtual tridimensional realista, em tempo-real, vendo as cenas alteradas como resposta aos seus comandos, como ocorre nos videogames atuais" Desse modo, a interação seria "mais rica e natural, gerando mais engajamento e eficiência" (p.8). Assim, observa-se que, conforme essas análises, o fator motivacional está estritamente ligado à questão da interatividade entre máquina e homem.

Ainda perduram alguns questionamentos sobre fatores subjetivos que circundam a temática da motivação. Como processos motivacionais operam? $\mathrm{O}$ que afeta a motivação? Como a motivação pode ser fomentada? Tais questionamentos ainda estão em aberto, mas, segundo Schunk, Pintrich e Meece (2008), questões contextuais, incluindo fatores sociais e culturais, seriam necessários para estudos relativos à motivação e aprendizado. Assim, a motivação se constitui como um fenômeno complexo que depende de variáveis pessoais, sociais e culturais. Para os referidos pesquisadores, motivação é o processo pelo qual a atividade direcionada a um objetivo é instigada e sustentada. Em relação ao processo, ela seria inferida a partir de ações e verbalizações, e quanto ao objetivo, seria expressa a partir do fato de que os indivíduos podem estar cientes sobre o que pretendem alcançar.

De acordo com Pintrich (2003), a influência da motivação na aprendizagem se daria a partir do interesse do aluno na realização de tarefas, do investimento em esforço para atingir objetivos e do uso efetivo de estratégias de aprendizado. Os indícios de motivação poderiam ser observados, então, a partir de três aspectos, segundo o autor: a) Escolha de tarefas - o que é de interesse dos alunos pode indicar aspectos motivacionais; b) Esforço - alunos motivados estariam dispostos a dedicar esforço (aplicar estratégias cognitivas) para alcançar um objetivo; c) Persistência - tempo despendido na realização de tarefas.

Inicialmente, os estudos de motivação abarcavam uma visão com foco em causas internas e seguiam um viés behaviorista e ambientalista, a partir do qual o estímulo do indivíduo seria incitado através de reforço e recompensa (Schunk, Pintrich e Meece, 2008). No entanto, hoje se acredita na influência dos pensamentos, crenças e emoções do sujeito para que fatores relacionados à motivação sejam avaliados. Conforme Barron e Harackiewicz (2001), alunos motivados a aprender estariam mais aptos a se engajar em atividades promotoras de aprendizado, e haveria uma relação recíproca, visto que a motivação pode influenciar o aprendizado e vice-versa. Desse modo, pode-se pensar que a questão da interatividade em interfaces não-convencionais está justamente em fornecer ao usuário a permissão de alterar/construir o seu ambiente de aprendizagem. Pode haver autonomia na escolha das ferramentas e na seleção de estratégias de ação por parte do aluno. Ele pode, então, manter uma postura mais autônoma em face da responsabilidade pela construção do seu conhecimento, a partir de um processo baseado em sua motivação.

Inclusive Rogers (1969), um dos primeiros estudiosos a trabalhar com a idéia de aprendizado significativo, assim como Ausubel (1963), partia da idéia de motivação para caracterizar essa aprendizagem. Conforme o autor, o aprendizado significativo envolveria envolvimento pessoal, que seria iniciado pelo próprio indivíduo e avaliado pelo aprendiz. Desse modo, o indivíduo partiria do seu interesse para encetar seu processo de construção de aprendizagem. No entanto, ainda nos perguntamos quais mecanismos poderiam ser capazes de fomentar no aprendiz um empenho e curiosidade na educação. Acredita-se que as interfaces não-convencionais podem se constituir em vetores de motivação para o aprendizado, visto que o aluno pode entrar em contato, a partir delas, com práticas que se constituem em experiências estésicas. 


\title{
4.2. Estética e Estesia
}

A palavra estética origina-se do termo grego aisthetikós, que, por sua vez, deriva de aisthanasthai, com o sentido de perceber, sentir (Ramalho e Oliveira, 2005). Foi empregada pela primeira vez, com o mesmo sentido da atualidade, no século XVIII, pelo filósofo alemão Alexander Von Baungarten, embora em tempos remotos já houvesse discussões a respeito da natureza da arte, do belo e de como o ser humano o sentia (Ramalho e Oliveira, 2005).

Com a introdução das tecnologias digitais na arte, surge a media art e a arte interativa, propondo uma revolução no discurso estético: evitar a teoria estética centrada no objeto de arte e optar pela relação obra - espectador, transformando o observador em interator (Giannetti, 2006). A partir da proposição dessas transformações surge um pensamento a respeito de uma estética digital, considerada como aquela que admite a máquina como "ser pensante", ou seja, também um interlocutor. Essa estética se baseia na ideia de que a relação homem-máquina possibilita ao sujeito o desenvolvimento de novos pensamentos e a criação de novidades (Giannetti, 2006). Desse modo, a partir da integração da teoria da estética digital ao conceito de design pedagógico, objetiva-se elaborar um novo discurso estético de MEDs, focado na relação sujeito-MED, de modo a admitir o sujeito como interator e possibilitando um diálogo com o sistema.

A estesia, por sua vez, é originada do grego, da palavra aisthesis, que significa basicamente a capacidade sensível do ser humano para perceber e organizar os estímulos que alcançam o seu corpo (Júnior, 2001). Para Dewey (1980), a experiência é estética quando todo o sujeito se envolve com sua cognição, sua emoção e a sua vida. De modo a delimitar os conceitos de estesia e estética, Murata (2009, p.46) delineia a seguinte distinção:

\begin{abstract}
A diferença entre estesia e estética está na origem motivadora das sensações percebidas no mundo exterior: a primeira privilegia a percepção de sensações naturais, originada no homem espontaneamente no interior de seu ser; a segunda, sensações norteadas por julgamentos ou reflexões desse homem conforme normas originadas em seu exterior, ou seja, nos grupos sociais
\end{abstract}

Assim, em meio ao contexto entre o visualizar e o sentir é que Greimas (1989) situa a estética, reportando-a à percepção de sensações através de relações recíprocas entre o inteligível e o sensível. Desse modo, entende-se que o objetivo da estética é surpreender o sujeito, para então se fazer notar, seja através do belo ou do feio, do agradável ou do irritante - o importante é possibilitar que o observador construa efeitos de sentido para o objeto em análise.

Nessa concepção greimasiana, a arte (através da estética) dá forma ao conteúdo para que o seu significado inteligível seja interpretado através dos sentidos. Porém, há várias metodologias de aplicação. No âmbito da educação, não há o objetivo de utilizar a estética para condicionar o sujeito, embora o método tradicional de ensino algumas vezes demonstre o contrário, quando teorias são simplesmente repassadas aos alunos através de conteúdos pré-definidos. Isso ocorre porque a educação tradicional costuma focalizar o conhecimento inteligível, causando uma sobreposição desse sobre o saber sensível. Porém, essa nova geração digital parece estar disposta a lidar com as sensações, com o sensível, através da incorporação em seus cotidianos de interfaces não-convencionais. $\mathrm{Na}$ adaptação dessas interfaces ao contexto educacional é preciso unir o saber sensível ao inteligível, numa relação de equilíbrio entre ambos. A 
experiência estética atua como forte aliada a esse objetivo. Segundo a semiótica greimasiana, haveria uma possibilidade de transformação da relação sujeito-objeto através da ruptura das ações automatizadas. Permite que o indivíduo construa efeitos de sentido, uma vez que se opõe aos condicionamentos da dessemantizada rotina cotidiana, estabelecendo um "novo estado de coisas" (Greimas, 2002).

Por meio da experiência estética considera-se o aluno como sujeito da construção do conhecimento, de modo a possibilitar que ele elabore um efeito de sentido para o seu objeto de estudo e não simplesmente aceite um determinado conceito. É nessa relação de equilíbrio entre o agir e o sentir que a semiótica greimasiana atua. Através da aplicação dessa semiótica na educação, portanto, objetiva-se colocar em prática as relações entre interatividade com interfaces não-convencionais e o processo de motivação do aluno.

A proposta de aplicação da semiótica greimasiana na elaboração de MEDs objetiva a contemplação de uma prática pedagógica que considere o pensamento crítico do aluno como parte integrante do conteúdo a ser abordado. Quando se pensa, então, na elaboração de MEDs que siga essa aplicação, é inevitável o fator da emoção e das sensações que tais materiais podem provocar no aluno. Para tanto, a essência dessa questão está na relação entre o plano de conteúdo e o plano da expressão. Primeiramente, o plano do conteúdo refere-se ao significado do texto, ou seja, o que ele está comunicando e de que maneira. Já o plano de expressão refere-se à manifestação desse conteúdo num sistema de significação verbal (línguas naturais), não-verbal (música, imagem, entre outros) ou sincrético (aquele que une vários tipos de linguagem). A partir das ideias propostas por Greimas (2002) é possível analisar como o plano da expressão e do conteúdo se relacionam através da estética e podem possibilitar uma experiência estésica ao usuário do MED. Pode-se, então, inferir que o contato com interfaces não-convencionais é passível de gerar relações estéticas com aquele que interage com essa interface. Na estética clássica, a ação do sujeito prevalece sobre a do objeto (do ponto de vista semiótico), há um deslumbramento pelas formas e luz, na direção da perfeição. Na estética da graça, a ação do sujeito já não é tão soberana sobre a do objeto, que o fascina, o seduz. Na estética da revelação, a atividade do objeto sobressai à do sujeito. Relaciona-se ao excesso, o objeto intimida o sujeito por meio do sincretismo visual, olfativo e tátil. Na estética da penetração o objeto atrai ao mesmo tempo em que afasta o sujeito por provocação, a partir da decomposição visual da forma, recursos cromáticos e táteis. Já na estética da purificação o objeto absorve o sujeito e ambos se dissolvem. Cabe ressaltar que a relação sujeito-objeto na experiência estética está sendo analisada sob um prisma paralelo ao de Piaget (1990). Nela, tanto o sujeito pode dominar o objeto, como pode ser absorvido por ele. A dominação do sujeito pelo objeto refere-se ao envolvimento, à penetração do usuário no objeto através da experiência estética, como, por exemplo, ocorre nos jogos de videogame ou no mundo simulado. Nesses casos, o usuário penetra ativamente no mundo virtual de modo a, naquele momento, tornar-se real. Nesse sentido ocorreria uma dominação do objeto sobre o sujeito. No entanto, esse domínio do objeto nada tem a ver com a submissão do aluno. Seria exatamente o contrário, pois somente a partir da postura autônoma, ativa e de abstrações que essa relação é construída pelo aluno na experiência estética. Desse modo, a relação semiótica greimasiana integra-se à interação sujeito-objeto de Piaget (1990), pois ambas baseiam-se na ação ativa do sujeito e na sua relação com o objeto.

As experiências estéticas intermediadas pelos meios digitais, incluindo-se os MEDs, em especial se utilizarem de interfaces não-convencionais, têm a possibilidade de tornarem-se mais envolventes do que outras mídias, pois o usuário participa ativamente da experiência, sendo um integrante da relação com o dispositivo. Pode, 
então, ocorrer uma experiência estética mais intensa que talvez se traduza em oportunidade de aprendizagem. Entretanto, a simples aplicação de diferentes mídias e interfaces interativas não é suficiente para a obtenção de uma experiência estética. Torna-se de fundamental importância diferenciá-la de uma simples experiência sensorial. A simples sensação, por exemplo, é uma experiência sensorial. É preciso "combinar e articular os dados sensórios simples (luzes, cores, sons) numa configuração que carregue um significado maior do que a mera soma de pequenas experiências sensoriais" (Greimas, 2002). Assim, a experiência possibilitada pelo material educacional digital será considerada uma experiência sensível no momento em que permitir a realização de relações por parte do sujeito, de modo a denotar um sentido, ou seja, "uma significação que se espraia para além dos estímulos elementares provenientes dos materiais empregados" (Greimas, 1989). As interfaces nãoconvencionais parecem justamente trazer uma experiência que vai além da simples sensação e podem, portanto, ser uma alternativa no uso de materiais educacionais. Tal interface, que implica numa experiência estética, colabora na construção de uma abordagem sincrética. Juntamente com a arte, aplica o simbolismo ao conteúdo, com a possibilidade de surpreender o sujeito e, a partir desse estranhamento, instigá-lo a investigar um efeito de sentido para um determinado objeto de estudo - fato que se relaciona com a motivação.

\section{Considerações Finais}

Esta pesquisa parte de algumas noções sobre motivação e sobre estética para refletir sobre como os aprendizes podem ser afetados pelas interfaces nãoconvencionais. É possível, então, que a partir da aplicação da tecnologia digital em materiais educacionais, o aluno se sinta instigado a explorar o objeto de estudo em questão e encontre liberdade para elaborar e testar hipóteses. Espera-se com isso, inclusive, ampliar a noção de interatividade na escola, de modo a colaborar na inserção de MEDs voltados ao sujeito - a partir de sua motivação e suas sensações fomentadas por experiências estéticas. A elaboração de MEDs, em muitos contextos, já ultrapassou o paradigma da simples digitalização de materiais analógicos. Essa construção de materiais pode, então, ser apoiada agora pela inclusão de interfaces não-convencionais, que podem atuar como disparadores de oportunidades de aprendizagem. O intuito é propor a transformação do caráter reprodutor de MEDs, ampliando o conceito de interatividade e colaborando na construção de MEDs voltados à ação do sujeito.

Em relação a implicações para estudos futuros relativos a essa temática, pretende-se desenvolver um estudo de caso com dez alunos universitários, de aproximadamente 20 anos, que utilizarão a mesma interface não-convencional com conteúdo holográfico sobre física, a fim de que suas reações e motivação, em realização ao uso do dispositivo, sejam observadas. Para a análise do feedback de cada usuário, os dados serão coletados a partir das seguintes fases: a) Observação direta, na qual as reações dos alunos serão observadas quando do uso da interface não-convencional (tal fase será gravada em vídeo); b) Auto-relato, em que o indivíduo fará um relato oral sobre sua experiência de utilização da interface; c) Sessão de visionamento, na qual o aluno observará a gravação que foi realizada da primeira fase e comentará suas reações. Assim, será feito uma averiguação de como as interfaces não-convencionais podem afetar o usuário aluno e a sua trajetória de aprendizagem. 


\footnotetext{
${ }^{1}$ A interface informática designa um conjunto de aparelhos e materiais que possibilitam a comunicação entre um sistema informático e os humanos (Lévy, 1993).

${ }^{2}$ Material educacional digital (MED) é conceituado por esta pesquisa como sendo todo o material voltado à aprendizagem e que utiliza um ou mais recursos digitais na sua elaboração.

${ }^{3}$ O termo "geração digital" reporta às pessoas que nasceram a partir de 1980 e que cresceram numa sociedade fortemente apoiada pelas tecnologias digitais (Veen e Vrakking, 2009).
}

\section{Referências}

AUSUBEL, D. The Psychology of Meaningful Verbal Learning. New York: Grune \& Stratton, 1963.

ALDRICH, C. Learning online with games, simulations and virtual worlds. San Francisco, CA, Jossey-Bass, 2009.

BARRON, K.; HARACKIEWICZ, J. Achievement goals and optimal motivation: testing multiple goal models. Journal of personality and social psychology, v.80, p.706-722, 2001.

BEHAR, P. MACEDO, A.; AMARAL, C.; ALBA, C.; SCHNEIDER, D.; LONGHI, M.; BERCHT, M.; BERNARDI, M.; BECKER, M.; NOTARE, M.; WALQUIL, M.; LEITE, S.; MORESCO, S.; FROZI, A. (Org.) Modelos pedagógicos em educação a distância. Porto Alegre: Artmed, 2009.

CAETANO, A. M. Interfaces Hápticas. In: $\mathbf{7}^{\mathbf{0}}$ Encontro Internacional de Arte e Tecnologia, 2008, Brasília. $7^{\circ}$ Encontro Internacional de Arte e Tecnologia, 2008.

DEWEY, J. Tendo uma experiência. In: DEWEY, J. Os Pensadores. São Paulo: Abril Cultural, 1980, p.89- 105.

GIANNETTI, C. Estética Digital: sintopia da arte, a ciência e a tecnologia. Belo Horizonte: C/Arte, 2006.

GREIMAS A. J.; Courtés. Dicionário de Semiótica. Trad. De Alceu Dias Lima e outros. São Paulo, Cultrix, 1989.

GREIMAS A. J. Da Imperfeição. São Paulo: Hacker Editores, 2002.

GREIS, L.; REATEGUI, E. Um simulador educacional para disciplina de física em mundos virtuais. RENOTE - Revista Novas Tecnologias na Educação, v.8, n.2, 2010 .

KAUFMAN, H.; SCHMALSTIEG, D. Mathematics and geometry education with collaborative augmented reality. Computers and Graphics, v.27, n.3, 2003.

KIRNER, C. Sistemas de Realidade Virtual. Departamento de Computação. Universidade Federal de São Carlos - UFSCar. (s.d) Disponível em: <http://www2.dc.ufscar.br/ grv/tutrv/tutrv.htm> Acesso: 11 maio 2011.

KIRNER, C.; SISCOUTTO, R. Realidade virtual e aumentada: conceitos, projetos e aplicações. In: Symposium on virtual and augmented reality. Symposium on virtual and augmented reality, 2007.

KIRNER, C.; ZORZAL, E. Aplicações Educacionais em Ambiente Colaborativos com Realidade Aumentada. SBIE2005 - XVI Simpósio Brasileiro de Informática na 
Educação, 2005, Juíz de Fora-MG . XVI Simpósio Brasileiro de Informática na Educação. v. 1, p. 114-124.

JÚNIOR, J. O sentido dos sentidos: a educação (do) sensível. Curitiba: Criar Edições, 2001.

LIU, W.; CHEOK, A.; MEI-LING, C.; THENG, Y. Mixed-reality classroom - Learning from entertainment. Proceedings of the 2nd international conference on Digital interactive media in entertainment and arts, vol. 274, Perth, Australia: 2007.

MURATA, E. Literatura e imaginário em 'leito de folhas verdes'. Letras de Hoje, Porto Alegre, v.44, n. 4, p.46-55, out./dez. 2009.

PIAGET, Jean. Epistemologia genética. São Paulo: Martins Fontes, 1990.

PINTRICH, P. Multiple goals, multiple pathways: the role of goal orientation in learning and achievement. Journal of Educational Psychology, v.92, p. 544-555, 2003.

RAMALHO E OLIVEIRA, S. Imagem também se lê. São Paulo: Edições Rosari, 2005.

ROGERS, C. Freedom to learn. Columbus: Merril, 1969.

SCHUNK, D.; PINTRICH, P.; MEECE, J. Motivation in Education: Theory, research, and applications. New Jersey: Pearson, 2008.

SMITH, C. Human factors in haptic interfaces. Crossroads: The ACM Student Magazine, mar 1997.

VEEN, W.; VRAKKING, B. Homo Zappiens: educando na era digital. Porto Alegre: Artmed, 2009. 